\title{
Considering mindfulness techniques in school-based anti-bullying programmes
}

\author{
Mairéad Foody ${ }^{1 *}(\mathbb{0}$, Muthanna Samara² \\ 'Department of Psychology, Mynooth University, Ireland \{mairead.foody@mu.ie\} \\ 2Department of Psychology, Kingston University London, United Kingdom \{M.Samara@kingston.ac.uk\}
}

Received on 19 May 2017; revised on 6 June 2017; accepted on 5 September 2017; published on 15 January 2018

\begin{abstract}
Schools have a duty of care to all students and to directly prevent and intervene with bullying amongst children and adolescents. The emergence of cyberbullying escalates this responsibility as the strategies that have become appropriate at national levels for bullying do not always parallel over to online environments. The impact on mental health is the most obvious concern for those responsible for reducing bullying, however, input from psychologists and mental health professionals is scant and often limited on this topic. This paper outlines what bullying is and the devastating impact it can have on the mental health of those involved. It will outline the most common anti-bullying initiatives as well as the current psychological and educational techniques, which could also be used to alleviate distress associated with bullying involvement. We will focus specifically on the role of mindfulness techniques and argue for more of such exercises to be included in whole-school bullying programmes. We conclude by arguing the need to investigate components relevant to both mindfulness and anti-bullying programmes (e.g., empathy, perspective-taking) as active ingredients for reducing the impact of bullying on mental health.
\end{abstract}

KEYWORDS: BULLYING, CYBERBULLYING, MENTAL HEALTH, MINDFULNESS, ANTI-BULLYING

\section{INTRODUCTION}

Reducing violence against children is a key focus for the United Nations (UN) and represents one of the sustainable development goals (United Nations, 2013). Under this agenda, there has been an increased interest in reducing bullying, including cyberbullying, in child and adolescent populations. There are currently a wide range of charities, non-profit organisations (NGOs), governmental organisations, academic institutions and educational bodies working against bullying and attempting to increase awareness of its impact and subsequently decrease prevalence rates. Similar aims can be found in many governmental agendas (e.g., National Action Plan against Bullying in Ireland), the World Health Organisation (WHO; Srabstein \& Leventhal, 2010) and the UN (United Nations, 2013). In general, this momentum has been established at a global level and even countries and regions not typically active at reducing traditional bullying appear to be

*To whom correspondence should be addressed: considering the risks of cyberbullying on their citizens (e.g., Qatar; Foody, Samara, El Asam, Morsi, \& Khattab, 2017). There are many reasons why this might be the case, not least the realisation that preventing cyberbullying requires a globalised approach due to its very nature and the lack of borders associated with the internet. There is also general concern that cyberbullying can have a more devastating impact on victims compared to traditional bullying in terms of mental health (e.g., Tokunaga, 2010).

While trying to understand the phenomena of bullying and cyberbullying, research has provided much needed insights into child and adolescent development, such as the association of childhood trauma and psychopathology in later life (e.g., Arseneault et al., 2011). Children do not develop in isolation, they both actively shape and are shaped by the social worlds in which they live. A child's personality, interests and activities are firmly located in the interactions between a child and the network or system to which each child belongs (Bronfenbrenner, 1979; Hill \& Tisdall, 1997). Their thoughts, feelings, characteristics and personalities develop in a variety of contexts or ecologies, which surround the individual and play a major role in their development (Bronfenbrenner, 1977; 1989). In this way, exposure to harassment or negative actions in childhood can directly influence their social and emotional development. Bullying provides the best example of this. Experiences of bullying in childhood and adolescence are related to poorer health and wealth in adulthood (Wolke, Copeland, Angold, \& Costello, 2013). In addition, bullying often leads to more violence and increases the risk of carrying a weapon to school (Ybarra, Diener-West, \& Leaf, 2007). It is also considered a high burden on the emergency services in the United States (Waseem, Ryan, Boutin Foster, \& Peterson, 2013). Buffering the negative social, emotional and psychological implications of bullying is therefore a cost-effective and appropriate manner to influence and reduce adults presenting with mental health difficulties in later life. Indeed, there needs to be more input from psychological and health services at the early intervention stage.

This paper will focus on the relationship between bullying experiences and mental health. It will also argue that victims of peer bullying in school or cyberspace should be considered a high risk population for the development of a range of social, emotional and psychological problems throughout the duration of the bullying, immediately after the incident, and in the long-term. We will introduce mindfulness techniques as a means of targeting and alleviating these effects.

Department of Psychology, Maynooth University, Co.Kildare, Ireland 


\section{WHAT IS BULLYING AND CYBERBULLYING?}

The most prevalent definition of traditional bullying is one put forward by Olweus (1997) who defined it in the traditional sense as when "a student is exposed, repeatedly and over time, to negative actions on the part of one or more students". To constitute bullying behaviour there must also be an imbalance in power between the perpetrator and his/her victim(s). Cyberbullying refers to when this negative behaviour occurs online or using technology or mobile phones (Smith et al., 2008). The core elements of intentionality, repetitiveness and power imbalance hold true for the definition of cyberbullying. However, the methods and means of causing harm vary greatly. Cyberbullying can consist of threats, verbal abuse, the spreading of images and videos, defamation and identity threat (O’Moore, 2014). In general, posting a video or an image of someone online once, but in a manner that can be shared several times, constitutes cyberbullying. In contrast, sending an email with mean or hurtful comments to someone once might constitute cyber aggression and will only be considered 'bullying' if the bully repeats the action (O'Moore, 2014). There are some immediate differences between traditional bullying and cyberbullying which increase the risk for psychological impact on the victim. The invasive nature of a cyberbullying incident in that it can happen in one's own home and the potential for a larger audience, can contribute to increased levels of shame, embarrassment, humiliation and a feeling of a lack of control for the victim. It can also make it more difficult to prove a cyberbullying incident, as the identity of the perpetrator can be kept anonymous and there are often no witnesses to the initial posting or sharing of the photo, video or information.

Although offline and online peer relationships may differ in the types of interactions between people (e.g., physical interaction versus sharing of pictures), and in relation to the points mentioned above, research has shown that the elements of cyberbullying often synchronise with the behaviours and elements of traditional bullying. Indeed, a widely-studied risk factor for cyberbullying is involvement in traditional bullying (Hemphill \& Heerde, 2014). There are concerns that involvement in one type of bullying (e.g., traditional) can increase the chances of being involved in a different type (e.g., cyber) and thus have a greater and combined effect on the social, emotional and psychological health of those involved (Hesapcioglu \& Ercan, 2017).

\section{CONSEQUENCES OF BULLYING AND CYBERBULLYING}

Regardless of the methods used, research has demonstrated a significant link between bullying experiences (traditional and/or cyber) and social, behavioural and psychological problems. For traditional bullying, exposure to such incidences has been associated with anxiety (Stapinksi et al., 2014; Pabian \& Vandebosch, 2016), depression and suicidal behaviour (Bauman, Toomey, \& Walker, 2013), eating disorders (Copeland et al., 2015), borderline personality disorder (Wolke, Shreier, Zanarini, \& Winsper, 2012), lower self-esteem (O'Moore \& Kirkham, 2001) and psychosomatic problems (Fekkes, Pijpers, \& Verloove-Vanhorick, 2004). Lower school achievement (Nakamoto \& Schwartz, 2010), higher school delinquency (Barboza, 2015) and school dropout (Cornell, Gregory, Huang, \& Fan, 2013) are also attributed to victimisation. Students in schools with high levels of reported bullying perform poorer academically than those with lower prevalence (Strøm, Thoresen, Wentzel-Larsen, \& Dyb, 2013). Bullies appear to have increased risk of involvement in criminality later in life (Ttofi,
Farrington, \& Lösel, 2012) and illicit drug use (Niemelä et al., 2011). The most at-risk group appear to be bully-victims (those who are both perpetrators and victims of bullying). These individuals appear to have increased risk of psychological problems compared to pure victims (Chang et al., 2013; Lereya, Copeland, Zmmit, \& Wolke, 2015), lower social competence and poorer problem solving skills (Cook, Williams, Guerra, Kim, \& Sadek, 2010).

Negative outcomes have also been documented for individuals specifically involved in cyberbullying. Victims have demonstrated loneliness and depressive mood (Olenik-Shemesh, Heiman, \& Eden, 2012) lower self-esteem (Patchin \& Hinduja, 2010) and higher levels of depression and suicide (Hinduja \& Patchin, 2010). Cyber victimisation has also been linked to school absenteeism and academic problems (Grinshteyn \& Yang, 2017; Tsitsika et al., 2015). Being a cyber bully has been linked to conduct problems, low prosocial behaviour and not feeling safe in school (Sourander et al., 2010), while bully-victims are shown to have increased risk of mental health problems (Kowalsi \& Limber, 2013).

Overall, these outcomes demonstrate the need for bullying and cyberbullying to be considered 'high risk' experiences for the immediate and the later development of mental health problems in children and young people. Indeed, appropriate early intervention could reduce the number of individuals presenting to mental health services in the future. One pilot study by Dyer and Teggart (2007) found that $62.5 \%$ of their sample $(\mathrm{N}=26)$ of users of the Child and Adolescent Mental Health Services in Northern Ireland had previous experience of bullying in school or their neighbourhoods. In general, the literature suggests that all young children and adolescents who are exposed to bullying should be considered 'high risk' for the development of psychopathology at some stage in their life.

\section{CURRENT ANTI-BULLYING PROGRAMMES}

Schools are the obvious place for anti-bullying programmes considering most children attend school at some stage in their life and by its very nature interaction with peers is mandatory. Furthermore, schools play an important role in student's social lives (Bond et al., 2004) and in promoting a safe and secure environment is often a primary concern and considered a prerequisite for student learning and attendance (Langford et al., 2015). Bullying interventions and prevention strategies often take the form of anti-bullying policies (Smith et al., 2012) and/or school-wide educational programmes (Samara \& Smith, 2008; Smith \& Sama$\mathrm{ra}, 2003)$. In general, there is a recognition that there is a need for standard and set procedures on how to prevent and deal with bullying and cyberbullying. These 'guidelines' often take the form of anti-bullying (and/or anti-cyberbullying) policies which are usually developed, updated and generated by schools and school staff. This policy should take into account the changing face of bullying and make allowances for new trends in cyberbullying behaviours that often evolve alongside new technological developments. It should also outline the steps to be followed when a bullying or cyberbullying incident occurs such as parent consultation, repercussions for bullies and incident reports. In many countries it is a legal requirement for schools to have an anti-bullying policy (e.g., United Kingdom, Smith, Smith, Osborn, \& Samara, 2008), however in reality, the policy itself can vary greatly from school to school and country to country (Foody et al., 2017). Follow-up of such policies normally happen at the national level and it can be beneficial when information can be fed back to respective education departments. An example of this is the National Action 
Plan on Bullying (2013) implemented by the Irish Department of Education and Skills. This action plan provides a set of recommendations to schools on the development of their policy and procedures for dealing with bullying incidents. For example, it suggests the provision of a definition of bullying, information on the impact and characteristics of the behaviour and a template for schools to develop their own anti-bullying and anti-cyberbullying policies.

School-wide programmes often include both policy and prevention strategies with a view to changing attitudes and behaviours in all parties involved (i.e., teachers, students, practitioners and parents). In general, the literature has found such programmes to be useful in the reduction of bullying. For example, one cochrane review of school-based anti-bullying interventions showed a reduction of $17 \%$ for reports of victimisation (Langford et al., 2015). The most widely recognised anti-bullying programme is the Olweus Bullying Prevention Programme (OBPP). Olweus (1997) was the first to create a comprehensive and empirically valid intervention that has been replicated and administered in schools around the world. The OBPP targets peer relationships to decrease existing bullying relationships, prevent new ones and to increase peer social relationships throughout the school (Olweus \& Limber, 2010). Parents, teachers, students and the community are encouraged to work together to reduce bullying rates. The programme has been extensively researched over the last decade and has demonstrated reductions in school bullying for different age groups across the globe (Yaakub, Haron, \& Leong, 2010). For example, Olweus and Limber (2010) reported a 5\% reduction in school bullying in 56 schools. Furthermore, this study demonstrated that the reduced bullying rates continue over time and as more cohorts in a school participated in the programme (Olweus \& Limber, 2010).

A more recent and popular anti-bullying programme is the KiVa anti-bullying programme that was developed in Finland in 2006. It considers bystanders to be an important element in reducing bullying behaviour and influencing the impact on victims (Salmivalli, 2010; Salmivalli, Voeten, \& Poskiparta, 2011). As such, one main objective of the intervention is to target bystanders and to increase their responsibility for intervening and reporting such incidences (Garandeau, Lee, \& Salmivalli, 2014). Several studies have demonstrated favourable results for this programme in terms of reducing the psychological impact of bullying experiences on students (Williford et al., 2013). For example, Kärnä et al. (2011) reported a reduction in peer and self-reported bullying in a sample of over 4,000 Finish students.

In addition to these two programme, there are many additional international programmes that have been established in various school settings and countries across the globe. A systematic review in 2008 found 30 different types of anti-bullying interventions worldwide (Ttofi \& Farrington, 2011). A subsequent review found that newly developed programmes were not only widely spread across the globe, but also reported various degrees of efficacy (Evans, Fraser, \& Cotter, 2014). For example, of the eighteen studies that demonstrated positive reductions in bullying rates, $13(72 \%)$ were conducted outside of the United States (i.e., Australia, Canada, Finland, Germany, Turkey, and United Kingdom). This raises the issue of culturally specific elements that might be unique to particular countries and which may influence the utility of an intervention. It is possible that some countries have less social inequality and as a result might find it easier to see a reduction in bullying rates once an intervention is implemented. On the other hand, societies with high social inequality and high prevalence of violence in the media might have more barriers in terms of changing the attitudes of their citizens towards aggression and bullying (Smith, Ananiadou \& Cowie, 2003).

Ttofi and Farrington (2011) found that the effectiveness of anti-bullying programmes increased with the age of participants. They also found that peer work did not appear to be a successful intervention approach, although others have argued that structured peer support schemes may provide protection from the negative associations of victimisation (Houlston, Smith, \& Jessel, 2011). Ttofi and Farrington (2011) suggested that a system of accrediting effective anti-bullying programmes should be developed. This might also be more efficient in terms of the time and cost of implementation. While worthwhile, one could argue that school-based interventions are limited in that they may not allow room for the individual responses to bullying incidents (Foody, Samara, \& Carlbring, 2015). One child may express their reaction to victimisation internally, where their self-esteem is affected. On the other hand, another student may express themselves with aggression or anger. In theory, school-based interventions should be able to cater for the individual needs of the students, in addition to creating a broader awareness of the problem (Jacobs, Völlink, Dehue, \& Lechner, 2014).

\section{PSYCHOLOGICAL INTERVENTION}

Despite the direct impact of bullying and cyberbullying on mental health, the health services are often far removed from dealing with these cases. Very often, interventions are left to the school and it becomes the responsibility of teachers and the wider school community to put a stop to the bullying. Although this may indeed lead to the reduction of bullying, school staff are not always appropriately skilled to deal with serious psychological issues. There is often no follow-up for those involved in terms of their mental health and/or their coping strategies. We know from the literature that such experiences can have long-lasting impact on victims and their mental health may continue to suffer passed the duration of the experiences. In some cases, psychological health can be effected on a larger and more long-term basis where symptoms are still present or even newly developed in adulthood. This calls for a stronger link between schools, parents and psychological services. It also calls for an increased awareness for health professionals to consider previous bullying experiences as a risk factor for psychopathology and to actively assess clients respectively. It is therefore essential to educate all health professionals on the tell-tale signs of victimisation and on the negative effects for those involved.

Of course, creating a standard therapeutic package for bullying involvement is something that would need to be considered with extreme caution. Expecting educational staff to intervene in serious matters relating to their student's mental health places a burden on schools that most do not have appropriate training for. This further complicates the issue and limits the possibility of blanket programmes for groups or classes of students. School-wide measures which follow a certain format (for all teachers and students) are easier and more straight forward to administer. Therefore, further research into the core components that victims of bullying might experience overall is important. Alternatively, investigating the core coping strategies that children and adolescents use in stressful situations may allow us to deduce some factors that could be built upon in interventions. For example, it has been found that bully-victims are more likely to use emotional coping strategies (e.g., irritation), while victims were more likely to use aggression (Völlink, Bolma, Dehue, \& Jacobs, 2013) when coping with stressful events. 
Despite the substantial risks to an individual after a bullying or cyberbullying experience, not all victims face such problems. Similar to risk factors, there are several aspects (e.g., personality strengths, home and family environment) that are positively related to coping skills and that promote resilience to negative experiences (Hernández de Frutos \& Del Olmo Vicén, 2014). Resilience is an important element in bullying research because it refers to the capacity to withstand and overcome stressful situations despite facing significant barriers (Luthar, Cicchetti, \& Becker, 2000). Consequently, understanding the elements that make victims (both traditional and cyber) more resilient and help them to recover from the incident faster is important when considering interventions. For example, social support has been demonstrated to reduce the odds of cyber victimisation (Ybarra, Mitchell, Palmer, \& Reisner, 2015) and friendships can mediate between bullying and depressive symptomology (van Harmelen et al., 2016).

\section{CONSIDERING MINDFULNESS}

At present, anti-bullying programmes are not equipped to provide individualised psychological support to victims as they normally rely on a whole school approach and standard care packages. On the contrary, there are established therapeutic packages that may lend themselves to such environments and which have already been established in classroom settings (e.g., mindfulness). Mindfulness concepts and techniques have attracted considerable attention in educational and school-based research in recent years. Two main benefits of using mindfulness techniques in the classroom are that they are relatively easy and quick to administer and have implications for increased well-being and resilience among students of all ages. Although many definitions of such a high-level concept are possible, it is widely agreed that mindfulness is a state of 'awareness that emerges through paying attention on purpose, in the present moment and nonjudgmentally' (Kabat-Zinn, 1994, p. 4). Baer, Smith and Allen (2004) previously argued that mindfulness comprises observing, describing, acting with awareness, and accepting without judgment. Hence, mindfulness techniques aim to facilitate present moment awareness and acceptance, in such a way that control exerted by psychological content (e.g., thoughts, feelings, emotions etc.) over behaviour is minimised. This can have direct positive consequences on behaviour, especially in relation to bullying. For example, mindfulness has been linked to empathy and perspective taking (Jones, Bodie, \& Hughes, 2016). Furthermore, empathy has been linked to positive bystander behavior (Barlińska, Szuster, \& Winiewski, 2015) which in turn has been linked to reductions in bullying (Polanin, Espelage, \& Pigoot, 2012).

The increasing integration of mindfulness concepts and techniques into classroom programmes and well-being initiatives in schools have resulted in teachers being relatively knowledgeable and practiced at delivering mindfulness programmes to their students. School-based mindfulness interventions have been linked to a range of positive outcomes for the stress level of teachers and the well-being of students (Taylor et al., 2016). For example, they have been linked to decreased inattentive and hyperactive behaviours (Klatt, Browne, Harpster, \& Case-Smith, 2012), reduced stress (van de Weijer-Bergsma, Langenberg, Brandsma, Oort, \& Bögels, 2012) and improved classroom behaviour (Black $\&$ Fernando, 2014) for the school-aged population. One recent study of Chinese children found that mindfulness moderated the effect of depression on victims of bullying (Zhou et al., 2017). Investigations of mindfulness techniques to buffer the impact of cyberbullying incidents are limited, however some studies have demonstrated an inverse relationship with non-judgmental stance and problematic internet use (Calvete, Gámez-Guadix, \& Cortazar, 2017).

Numerous studies provide empirical support for mindfulness techniques when presented within specific therapeutic packages which, in contrast to stand alone mindfulness techniques, are often developed for clinical samples. For example, Mindfulness-based Stress Reduction (MBSR) and Mindfulness Based Cognitive Therapy (MBCT) have been shown to reduce stress, pain, anxiety, and depression in individuals with clinical diagnosis (e.g., Goldin \& Gross, 2010; Segal, Williams, \& Teasdale, 2002). Furthermore, Acceptance and Commitment Therapy (ACT; Hayes, Strosahl ,\& Wilson, 1999), which includes mindfulness techniques, has shown positive results for a range of disorders including anxiety, depression and chronic pain (Arch et al., 2012; Buhrman et al., 2013; Folke, Parling, \& Melin, 2012). ACT is appropriate for school-based interventions as it aims to help students to become aware of, and understand their emotional responses to a challenging situation (such as peer bullying), decrease their avoidance of dealing with such emotions and increase problem solving skills (Foody et al., 2015; Theodore-Oklota, Orsillo, Lee \& Vernig, 2014).

While it may not be feasible to train teachers and school staff to a professional level in psychological therapies, it is feasible to ensure counsellors or school psychologists do understand their utility in dealing with bullying incidents. This calls for increased research into the use of standard therapeutic packages with victims of bullying and cyberbullying so that efficacy can be determined. Of course, not all schools are fortunate to have a mental health professional who could deliver tailored interventions to at-risk individuals. However, mindfulness techniques can be a proactive way to target well-being among students. If administered appropriately and regularly, they have the potential to increase perspective taking and to increase positive bystander behaviour. They can also increase positive psychological functioning in young adults, training positive coping skills and leading to positive mental health in the future. In addition, these techniques can be taught to teachers through appropriate workshops and integrated into the curriculum. More research is needed in this area to determine the utility of mindfulness techniques, if they can be incorporated into current anti-bullying strategies, or if we can develop anti-bullying interventions out of them. In particular, there is a need for more experimental studies where schools are randomized to different elements of interventions and/or components of interventions to shed light on their relative effectiveness (Smith, Salmivalli, \& Cowie, 2012). Indeed, such experimental componential analysis is common practice in mindfulness research (Forsyth, \& Hayes, 2014) allowing academics to decipher which exercises and techniques work in comparisons to others (e.g., Foody, Barnes-Holmes, Barnes-Holmes, Rai, \& Luciano, 2015)

\section{CONCLUSION}

Schools and parents are becoming increasingly aware of the devastating impact one incident of bullying and cyberbullying can have on their students and children. In particular, high profile media coverage of suicides has led adults to frenzied attempts to protect adolescents from online harassment. Some measures are more productive than others. For the most part, schools are turning their attention more and more to the well-being of their students and to programmes which can increase positive coping strategies and decrease mental health problems. It is astonishing 
that these two tracks do not appear to overlap. It is often the case that schools engage with one anti-bullying programme on a whole school level and do not link it back to mental health or well-being programmes that are often implemented separately. Such a restricted focus on bullying behaviour ignores the reality that a huge amount of bullying occurs because of a lack of tolerance for diversity, poor empathic skills and reduced sense of civic responsibility.We also appear to have two separate tracks in research and there is a need for more mindfulness-based anti-bullying research projects which will inform us of the important and active components in reducing bullying and increasing emotional intelligence, perspective-taking and empathy in our students.

\section{FUNDING}

Dr Foody is supported by the Irish Research Council of Ireland and Dr Samara is supported by the Qatar National Research Fund (QNRF) a member of Qatar Foundation Doha, Qatar, National Priority Research Programs grant (NPRP 5-1134-3-240). We thank both funding bodies for their support in this project.

\section{REFERENCES}

Arch, J., Eifert, G. H., Davies, C., Vilardaga, J. P., Rose, R. D., \& Craske, M. G. (2012). Randomized clinical trial of cognitive behavioral therapy (CBT) versus acceptance and commitment therapy (ACT) for mixed anxiety disorders. Journal of Consulting and Clinical Psychology, 80(5), 750-765. doi:10.1037/ a0028310

Arseneault, L., Cannon, M., Fisher, H. L., Polanczyk, G., Moffitt, T. E., \& Caspi, A. (2011). Childhood trauma and children's emerging psychotic symptoms: A genetically sensitive longitudinal cohort study. The American Journal of Psychiatry, 168(1), 65-72. doi:10.1176/appi.ajp.2010.10040567

Baer, R., Smith, G., \& Allen, K. (2004). Assessment of mindfulness by self-report: The Kentucky Inventory of Mindfulness Skills. Assessment, 11, 191-206. doi:10.1177/1073191104268029

Barboza, G. E. (2015). The association between school exclusion, delinquency and subtypes of cyber- and F2F-victimizations: Identifying and predicting risk profiles and subtypes using latent class analysis. Child Abuse \& Neglect, 39, 109122. doi:10.1016/j.chiabu.2014.08.007

Barlińska, J., Szuster, A., \& Winiewski, M. (2015). The role of short- and long-term cognitive empathy activation in preventing cyberbystander reinforcing cyberbullying behavior. Cyberpsychology, Behavior and Social Networking, 18(4), 241-244. doi:10.1089/cyber.2014.0412

Bauman, S., Toomey, R. B., \& Walker, J. L. (2013). Associations among bullying, cyberbullying, and suicide in high school students. Journal of Adolescence, 36 , 341-350. doi:10.1016/j.adolescence.2012.12.001

Black, D. S., \& Fernando, R. (2014). Mindfulness training and classroom behaviour among lower-income and ethnic minority elementary school children. Journal of Child and Family Studies, 23, 1242-1246. doi:10.1007/s10826-013-9784-4

Bond, L., Patton, G., Glover, S., Carlin, J. B., Butler, H., Thomas, L., \& Bowes, G. (2004). The Gatehouse Project: can a multilevel school intervention affect emotional wellbeing and health risk behaviours? Journal of Epidemiology and Community Health, 58, 997-1003. doi:10.1136/jech.2003.009449

Bronfenbrenner, U. (1979) The ecology of human development. Cambridge, MA: Harvard University.

Bronfenbrenner, U. (1977). Toward an experimental ecology of human development. American Psychologist, 32, 513-31. doi:10.1037/0003-066X.32.7.513

Bronfenbrenner, U. (1989) Ecological systems theory. Annals of Child Development, 6, 187-249.

Buhrman, M., Skoglund, A., Husell, J., Bergström, K., Gordh, T., Hursti, T., Bandelin, N., Furmark, T., \& Andersson, G. (2013). Guided internet-delivered acceptance and commitment therapy for chronic pain patients: A randomozed controlled trial. Behaviour Research and Therapy, 51(6), 307-15. doi:10.1016/j. brat.2013.02.010

Calvete, E., Gámez-Guadix, M., \& Cortazar, N. (2017). Mindfulness facets and problematic Internet use: A six-month longitudinal study. Addictive Behaviors, 72, 57-63. doi:10.1016/j.addbeh.2017.03.018

Chang, F. C., Lee, C. M., Chiu, C. H., Hsi, W. Y., Huang, T. F., \& Pan, Y. C. (2013). Relationships among cyberbullying, school bullying, and mental health in Taiwanese adolescents. Journal of School Health, 83, 454-462. doi:10.1111/ josh. 12050

Cook, C. R., Williams, K. R., Guerra, N. G., Kim, T. E., \& Sadek, S. (2010). Pre- dictors of bullying and victimization in childhood and adolescence: A meta-analytic investigation. School Psychology Quarterly, 25(2), 65-83. doi:10.1037/ a0020149

Copeland, W. E., Bulik, C. M., Zucker, N., Wolke, D., Lereya, S. T., \& Costello, E. J. (2015). Does childhood bullying predict eating disorder symptoms? A prospective, longitudinal analysis. International Journal of Eating Disorders, 48, 1141-1149. doi:10.1002/eat.22459

Cornell, D., Gregory, A., Huang, F., \& Xitao, F. (2013). Perceived prevalence of teasing and bullying predicts high school dropout rates. Journal of Educational Psychology, 105(1), 138-149. doi:10.1037/a0030416

Department of Education and Skills (2013). Action plan on bullying. Report of the anti-bullying working group to the Minister for Education and Skills (Report). Dublin: The Stationery Office. Retrieved from http://www.education.ie/servlet/ blobservlet/tl_3rdlevel_accessreport.pdf

Dyer, K., \& Teggart, T. (2007). Bullying Experiences of Child and Adolescent Mental Health Service-users: A Pilot Survey. Child Care in Practice, 13(4), 351-365. doi:10.1080/13575270701488733

Evans, C. B. R., Fraser, M. W., \& Cotter, K. L. (2014) The effectiveness of schoolbased bullying prevention programs: A systematic review. Aggression and Violent Behavior, 19(5), 532-44. doi:10.1016/j.avb.2014.07.004

Fekkes, M., Pijpers, F. I. M., \& Verloove-Vanhorick, S. P. (2004). Bullying behavior and associations with psychosomatic complaints and depression in victims. Journal of Pediatrics, 144, 17-22. doi:10.1016/j.jpeds.2003.09.025

Folke, F., Parling, T., \& Lennart, M. (2012). Acceptance and Commitment Therapy for depression: A preliminary randomized clinical trial for unemployed on long-term sick leave. Cognitive and Behavioral Practice, 19(4), 583-594. doi:10.1016/j.cbpra.2012.01.002

Forsyth, L., \& Hayes, L. (2014). The effects of acceptance, mindfulness or spontaneous coping on an experimentally induced pain task. Psychological Record, 64, 447-455. doi:10.1007/s40732-014-0010-6

Foody, M., Barnes-Holmes, Y., Barnes-Holmes, D., Rai, L., \& Luciano, C. (2015). An empirical investigation of the role of self, hierarchy, and distinction in a common ACT exercise. The Psychological Record, 65, 231-243. doi:10.1007/ s40732-014-0103-2

Foody, M., Samara, M., \& Carlbring, C. (2015). A review of cyberbullying and suggestions for online psychological therapy. Internet Interventions, 2, 235-242. doi:10.1016/j.invent.2015.05.002

Foody, M., Samara, M., El Asam, A., Morsi, H., \& Khattab, A. (2017). A review of cyberbullying legislation in Qatar: Considerations for policy makers and educators. International Journal of Law and Psychiatry, 50, 45-51. doi:10.1016/j. ijlp.2016.10.013

Garandeau, C. F., Lee, I. A., \& Salmivalli, C. (2014) Differential effects of the KiVa anti-bullying programme on popular and unpopular bullies. Journal of Applied Developmental Psychology, 35(1), 44-50. doi:10.1016/j.appdev.2013.10.004

Goldin, P. R., \& Gross, J. J. (2010). Effects of Mindfulness-Based Stress Reduction (MBSR) on Emotion Regulation in Social Anxiety Disorder. Emotion, 10(1), 83-91. doi:10.1037/a0018441

Grinshteyn, E., \& Yang, T. (2017). The association between electronic bullying and school absenteeism among high school students in the United States. Journal of School Health, 87, 142-149. doi:10.1111/josh. 12476

Hayes, S. C., Strosahl, K., \& Wilson, K. (1999). Acceptance and Commitment Therapy: An experiential approach to behavior change. New York: Guildford Press.

Hemphill, S. A., \& Heerde, J. A. (2014). Adolescent predictors of young adult cyberbullying perpetration and victimization among Australian youth. Journal of Adolescent Health, 55(4), 580-7. doi:10.1016/j.jadohealth.2014.04.014

Hernández de Frutos, T., \& Del Olmo Vicén, N. (2014). Factors of risk and protection/resilience in adolescent scholar bullying. Revista Internacional de Sociología, 72(3), 583-608. doi:10.3989/ris.2013.05.07

Hesapcioglu, S. T., \& Ercan, F. (2017). Traditional and cyberbullying co-occurrence and its relationship to psychiatric symptoms. Pediatrics International, 59, 16-22. doi: 10.1111/ped.13067

Houlston, C., Smith, P. K., \& Jessel, J. (2011). The relationship between use of school-based peer support initiatives and the social and emotional well-being of bullied and non-bullied students. Children and Society, 25(4), 293-305. doi:10.1111/j.1099-0860.2011.00376.x

Hill, M., \& Tisdall, K. (1997). Children and society. Harlow: Longman.

Hinduja, S., \& Patchin, J. W. (2010). Bullying, cyberbullying, and suicide. Archives of Suicide Research, 14, 206-221. doi:10.1080/13811118.2010.494133

Jacobs, N. C. L., Völlink, T., Dehue, F., \& Lechner, L. (2014). Online Pestkoppenstoppen: systematic and theory-based development of a web-based tailored intervention for adolescent cyberbully victims to combat and prevent cyberbullying. BMC Public Health, 14(1), 396. doi.org/10.1186/1471-2458-14-396

Jones, S. M., Bodie, G. D., \& Hughes, S. D. (2016). The impact of mindfulness on empathy, active listening, and perceived provisions of emotional support. Communication Research, 1-28. doi:10.1177/0093650215626983

Kabat-Zinn, J. (1994). Wherever you go, there you are: Mindfulness meditation in everyday life. New York: Hyperion Press. 
Kärnä, A., Voeten, M., Little, T. D., Poskiparta, E., Kaljonen, A., \& Salmivalli, C. (2011). A Large-Scale Evaluation of the KiVa Antibullying Program: Grades 4-6: Evaluation of KiVa Antibullying Program. Child Development, 82(1), 31130. doi:10.1111/j.1467-8624.2010.01557.x

Klatt, M., Browne, E., Harpster, K., \& Case-Smith, J. (2012). P04.35. Sustained effects of a mindfulness-based classroom intervention on behavior in urban, underserved children. BMC Complementary and Alternative Medicine, 12(1), 305. doi:10.1186/1472-6882-12-S1-P305

Kowalski, R., \& Limber, S. (2013). Psychological, physical and academic correlates of cyberbullying and traditional bullying. Journal of Adolescent Health, 53, 1320. doi:10.1016/j.jadohealth.2012.09.018

Langford, R., Bonell, C., Jones, H., Pouliou, T., Murphy, S., Waters, E., Komro K., Gibbs, L., Magnus, D., \& Campbell, R. (2015) The World Health Organization's Health Promoting Schools framework: A Cochrane systematic review and meta-analysis. MBC Public Health, 15, 130. doi:10.1186/s12889-015-1360-y

Lereya, S. T., Copeland, W. E., Zammit, S., \& Wolke, D. (2015). Bully/victims: A longitudinal, population-based cohort study of their mental health. European Child and Adolescent Psychiatry, 24, 1461-1471. doi:10.1007/s00787-0150705-5

Luther, S. S., Cicchetti, D., \& Becker, B. (2000). The construct of resilience: A critical evaluation and guidelines for future work. Child Development, 71(3), 543562. doi:10.1111/1467-8624.00164

Nakamoto, J., \& Schwartz, D. (2010). Is peer victimization associated with academic achievement? A meta-analytic review. Social Development, 19(2), 221-242. doi:10.1111/j.1467-9507.2009.00539.x

Niemalä, S., Brunstein-Klomek, A., Sillanmäki, L., Helenius, H., Piha, J., Kumpulainen, K., Moilanen, I., Tamminen, T., Almqvist, F., \& Sourander, A. (2011). Childhood bullying behaviours at age eight and substance use at age 18 among males. A national wide prospective study. Addictive Behaviors, 36, 256260. doi:10.1016/j.addbeh.2010.10.012

Olenik-Shemesh, D., Hieman, T., \& Eden, S. (2012). Cyberbullying victimisation in adolescence: relationship with loneliness and depressive mood. Emotional and Behavioural Difficulties, 17(3-4), 361-374. doi:10.1080/13632752.2012.704227

Olweus, D. (1997). Bullying/victim problems in school: Facts and intervention. European Journal of Psychology of Education, 12(4), 495-510. doi:10.1007/ BF03172807

Olweus D, \& Limber S. P. (2010). Bullying in School: Evaluation and Dissemination of the Olweus Bullying Prevention Program. American Journal of Orthopsychiatry, 80(1), 124-34. doi:10.1111/j.1939-0025.2010.01015.x

O'Moore, M. (2014). Understanding Cyberbullying: A guide for parents and teachers. Vertias: Ireland.

O'Moore, M., \& Kirkham, C. (2001). Self-esteem and its relationship to bullying behaviour. Aggressive Behavior, 27(4), 269-283. doi:10.1002/ab.1010

Pabian, S., \& Vandebosch, H. (2016). An investigation of short-term longitudinal associations between social anxiety and victimization and perpetration of traditional bullying and cyberbullying. Journal of Youth Adolescence, 45, 328-339. doi:10.1007/s10964-015-0259-3

Patchin, J. W., \& Hinduja, S. (2010). Cyberbullying and Self-Esteem. Journal of School Health, 80(12), 614-621. doi:10.1111/j.1746-1561.2010.00548.x

Polanin, J. R., Espelage, D. L., \& Pigott, T. D. (2012). A meta-analysis of schoolbased bullying prevention programs' effects on bystander intervention behaviour. School Psychology Review, 41(1), 47-65.

Salmivalli C. (2010) Bullying and the peer group: A review. Aggression and Violent Behavior, 15(2), 112-120. doi:10.1016/j.avb.2009.08.007

Salmivalli, C., Voeten, M., \& Poskiparta (2011). Bystanders matter: Associations between reinforcing, defending, and the frequency of bullying behavior in classrooms. Journal of Clinical Child \& Adolescent Psychology, 40(5), 668-676. doi $: 10.1080 / 15374416.2011 .597090$

Samara, M. M., \& Smith, P. K. (2008). How schools tackle bullying, and the use of whole school policies: Changes over the last decade. Educational Psychology, 28, 663-676. doi:10.1080/01443410802191910

Segal, Z. V., Williams, J. M. G., \& Teasdale, J. D. (2002). Mindfulness-based cognitive therapy for depression. New York: Guilford Press.

Smith, P. K., Ananiadou, K., \& Cowie, H. (2003) Interventions to Reduce School Bullying. The Canadian Journal of Psychiatry, 48(9), 591-599. doi:10.1177/070674370304800905

Smith, P. K., Mahdavi, J., Carvalho, M., Fisher, S., Russell S., \& Tippett, N. (2008). Cyberbullying: its nature and impact in secondary school pupils. Journal of Child Psychology and Psychiatry, 49(4), 376-85. doi:10.1111/j.14697610.2007.01846.x

Smith, P.K., Salmvialli, C., \& Cowie, H. (2012). Effectiveness of school-based programs to reduce bullying: A commentary. Journal of Experimental Criminology, 8(4), 433-441. doi:10.1007/s11292-012-9142-3

Smith, P. K., \& Samara, M. (2003). Evaluation of the DfES anti-bullying pack (research brief RBX06-03). London, UK: Department for Education and Skills.

Smith P. K., Smith, C., Osborn, R., \& Samara M. (2008). A content analysis of school anti-bullying policies: progress and limitations. Educational Psychology in Practice, 24(1), 1-12. doi:10.1080/02667360701661165

Smith, P. K., Kupferberg, A., Mora-Merchan, J. A., Samara, M., Bosley, S., \& Osborn, R. (2012). A content analysis of school anti-bullying policies: A follow-up after six years. Educational Psychology in Practice, 48, 47-70. doi:10.1080/02 667363.2011.639344

Sourander, A., Klomek, A. B., Ikonen, M., Lindroos, J., Luntamo, T., Koskelainen, M., Ristkar, T., \& Helenius, H. (2010). Psychosocial risk factors associated with cyberbullying among adolescents: A population based study. Archives of General Psychiatry, 67(7), 720-728. doi:10.1001/archgenpsychiatry.2010.79

Srabstein, J. C., \& Leventhal, B. L. (2010). Prevention of bullying-related morbidity and mortality: a call for public health policies. Bulletin of the World Health Organization, 88, 403. doi:10.2471/BLT.10.077123

Stapinski, L. A., Bowes, L., Wolke, D., Pearson, R. M., Mahedy, L., Button, K. S., Lewis, G., \& Araya, R. (2014). Peer victimisation during adolescence and risk for anxiety disorders in adulthood: A prospective cohort study. Depression and Anxiety, 31, 574-582. doi:10.1002/da.22270

Strøm, I. F., Thoresen, S., Wentzel-Larsen, T., \& Dyb, G. (2013). Violence, bullying and academic achievement: A study of 15-year-old adolescents and their school environment. Child Abuse \& Neglect, 37, 243-251. doi:10.1016/j.chiabu. 2012.10 .010

Taylor, C., Harrison, J., Haimovitz, K., Oberle, E., Thomson, K., Schonert-Reichl, K., \& Roser, R.W. (2016). Examining ways that a mindfulness-based intervention reduced stress in public school teachers: A mixed-methods study. Mindfulness, 7, 115-129. doi:10.1007/s12671-015-0425-4

Theodore-Oklata, C., Orsillo, S. M., Lee, J. K., \& Vernig, P. M. (2014). A pilot of an acceptance-based risk reduction program for relational aggression for adolescents. Journal of Contextual Behavioral Science, 3(2), 109-116. doi:10.1016/j. jcbs.2014.03.001

Tokunaga, R. (2010). Following you home from school: A critical review and synthesis of research on cyberbullying victimization. Computers in Human Behavior, 26, 277-287. doi:10.1016/j.chb.2009.11.014

Tsitsika, A., Janikian, M., Wójcik, S., Makaruk, K., Tzavela, E., Tzavara, C., Greydanus, D., Merrick, J., \& Richardson, C. (2015). Cyberbullying victimization prevalence and associations with internalizing and externalizing problems among adolescents in six European countries. Computers in Human Behavior, 51, 1-7. doi:10.1016/j.chb.2015.04.048

Ttofi, M. M., \& Farrington, D. P. (2011). Effectiveness of school-based programs to reduce bullying: a systematic and meta-analytic review. Journal of Experimental Criminology, 7(1), 27-56. doi:10.1007/s11292-010-9109-1

Ttofi, M. M., Farrington, D. P., \& Lösel, F. (2012). School bullying as a predictor of violence later in life: A systematic review and meta-analysis of prospective longitudinal studies. Aggression and Violent Behavior, 17(5), 405-418. doi:10.1016/j.avb.2012.05.002

United Nations Special Represenative of the Secretary-general on Violence Against Children (2013). Ending the torment: tackling bullying from schoolyard to cyberspace (Report). New York.

van Harmelen, A.-L., Gibson J. L., St Clair, M. C., Owens, M., Brodbeck, J., Dunn, V., Lewia, G., Croudace, T., Jones, P. b., Kievit, R. A., \& Goodyer, I. M. (2016) Friendships and family support reduce subsequent depressive symptoms in atrisk adolescents. PLoS ONE, 11(5). doi:10.1371/journal.pone.0153715

van de Weijer-Bergsma, E., Langenberg, G., Brandsma, R., Oort, F. J., \& Bögels, S. M. (2012). The effectiveness of a school-based mindfulness training as a program to prevent stress in elementary school children. Mindfulness, 5, 238-248. doi:10.1007/s12671-012-0171-9

Völlink, T., Bolman, C. A. W., Dehue, F., \& Jacobs, N. C. L. (2013). Coping with cyberbullying: Differences between victims, bully-victims and children not involved in bullying. Journal of Community and Applied Social Psychology, 23, 7-24. doi:10.1002/casp. 2142

Waseem, M., Ryan, M., Boutin Foste, C., \& Peterson, J. (2013). Assessment and management of bullied children in the emergency department. Pediatric Emergency Care, 29(3), 389. doi:10.1097/PEC.0b013e31828575d7

Williford, A., Elledge, L. C., Boulton, A. J., DePaolis, K. J., Little, T. D., \& Salmivalli, C. (2013). Effects of the KiVa Antibullying Program on cyberbullying and cybervictimization frequency among finnish youth. Journal of Clinical Child \& Adolescent Psychology, 42(6), 820-33. doi:10.1080/15374416.2013.787623

Wolke, D., Copeland, W. E., Angold, A., \& Costello, E. J. (2013). Impact of bullying in childhood on adult health, wealth, crime and social outcomes. Psychological Science, 24(1), 1958-1970. doi:10.1177/0956797613481608

Wolke, D., Schreier, A., Zanarini, M., \& Winsper, C. (2012). Bullied by peers in childhood and borderline personality symptoms at 11 years of age: A prospective study. The Journal of Child Psychology and Psychiatry, 53(8), 846-855. doi:10.1111/j.1469-7610.2012.02542.x

Yaakub, N. F., Haron, F., \& Leong, G. C. (2010). Examining the efficacy of the Olweus prevention programme in reducing bullying: the Malaysian experience. Procedia - Social and Behavioral Sciences, 5, 595-598. doi:10.1016/j. sbspro.2010.07.148

Ybarra, M. L., Diener-West, M., \& Leaf, P. J. (2007). Examining the overlap in Inter- 
net harassment and school bullying: implications for school intervention. Journal of Adolescent Health, 41(6), 42-50. doi:10.1016/j.jadohealth.2007.09.004

Ybarra, M. L., Mitchell, K. J., Palmer, N. A., \& Reisner, S. L. (2015). Online social support as a buffer against online and offline peer and sexual victimization among U.S. LGBT and non-LGBT youth. Child Abuse and Neglect, 39, 123136. doi:10.1016/j.chiabu.2014.08.006

Zhou, Z.-K., Liu, Q.-Q., Niu, G.-F., Sun, X.-J., \& Fan, C.-Y. (2017). Bullying victimization and depression in Chinese children: A moderated mediation model of resilience and mindfulness. Personality and Individual Differences, 104, 137142. doi:10.1016/j.paid.2016.07.040

How to cite this article: Foody, M., \& Samara, M. (2017).

Considering mindfulness techniques in school-based an-

ti-bullying programmes. Journal of New Approaches in Edu-

cational Research, 7(1), 3-9. doi: 10.7821/naer.2018.1.253 